\title{
Spatial analysis of morphological variation in African honeybees (Apis mellifera L.) on a continental scale
}

\author{
José A.F. Diniz-FILHo ${ }^{\mathrm{a} *}$, H. Randall HePBURN ${ }^{\mathrm{b}}$, Sarah RADLOFF ${ }^{\mathrm{c}}$, \\ Stefan FuCHS ${ }^{\mathrm{d}}$ \\ ${ }^{a}$ Departmento de Biologia Geral, ICB, Universidade Federal de Goiás, \\ C.P. 131, 74.001-970 Goiânia, GO, Brazil \\ ${ }^{\mathrm{b}}$ Department of Zoology and Entomology, Rhodes University, P.O. Box 94, \\ 6140 Grahamstown, South Africa \\ ${ }^{c}$ Department of Statistics, Rhodes University, P.O. Box 94, \\ 6140 Grahamstown, South Africa \\ d Institut für Bienenkunde (Polytechnische Gesellschaft), Fachbereich Biologie der J-W. Goethe \\ Universität Frankfurt am Main, Karl-von-Frisch Weg 2, D-61440 Oberursel, Germany
}

(Invited paper)

\begin{abstract}
Population differentiation of African honeybees has been analysed in a spatial context encompassing the continent's wide geographical range and environmental heterogeneity, based on 10 morphological characters measured from 268 local populations. While autocorrelation indicates a continuous large-scale decrease in similarity in general, clustering of single character correlograms suggests four distinct groups of profiles. This pattern, further supported by mapping factor scores, canonical trend surface analysis axes scores, suggests a variety of microevolutionary mechanisms acting at distinct scales in time and space in different groups of characters. Association with largescale differences in vegetation, climate and traditional subspecific classification has been analysed by analysis of variance (ANOVA). The most important aspect is that the results support the hypothesis that traditional subspecies, at least as defined by these characters, seem to represent integrated evolutionary units well adapted to their local conditions.
\end{abstract}

Apis mellifera / Africa / biogeography / spatial analysis

\footnotetext{
* Correspondence and reprints

E-mail: diniz@icb1.ufg.br
} 


\section{INTRODUCTION}

During the last 30 years, different multivariate statistical methods have been used to analyse honeybee populations worldwide [20]. In a generic sense, these methods have been used to visualise the relative position of observations (usually colony means) in a dimensional reduced space, defined by linear combinations of original morphometric characters. In most situations, the purpose is to test differences among a priori defined groups, especially subspecies $[12,20]$.

In recent years, it has been recognised that morphological and genetic variation among honeybee populations should also be investigated in a spatial context. There are many advantages to this approach. Firstly, since the microevolutionary processes related to population differentiation such as selection, migration and drift occur in a spatial context, it would be easier to infer these processes by analysing morphometric variation in geographic space. Secondly, since these processes usually produce at least partially continuous variation, the traditional approach of using discriminant analysis to test differences among subspecies is usually biased by the spatially structured differences within these groups $[5,12,18]$.

Two different approaches have been used to evaluate spatial variation in honeybees. The easier of these is to extend the traditional multivariate approaches, but showing their results in a geographic context by mapping and generating interpolated functions from scores derived from factor, principal component (PCA) or discriminant analyses [2]. In this case, samples are also taken in a spatial design, usually transects [13]. On the other hand, direct spatial analyses can also be performed, by pairing geographic coordinates (latitude and longitude) with mean vectors of local populations. Trend surface and spatial autocorrelation analyses have been used in these cases to assess population structure and attempt to make inferences about microevolutionary processes involved in population differentiation $[3,4,6,7]$.

Investigations about the population differentiation of African honeybees have been traditionally carried out by partitioning populations into different subspecies, since the findings of Kerr and Portugal-Araújo [15]. After the introduction of multivariate analyses into honeybee systematics, several different typologies have been proposed [12, 20]. Because of the wide geographical range and environmental heterogeneity throughout the continent, differentiation among African honeybees can provide insight into the microevolutionary processes involved in population differentiation, both in terms of stochastic processes such as drift and migration, but especially in terms of morphological, behavioural and physiological adaptations to different local conditions.

The African bees are smaller than the European subspecies, and form a more homogeneous cluster in multivariate space according to PCA [20]. Recently, Hepburn and Radloff [12] discussed the morphological variation in a different context, by analysing in detail patterns of spatial variation and admixture among spatially contiguous populations on a regional basis. In this paper, the main objective is to expand this approach and apply different spatial data analysis techniques to study the variation at continental scale for 10 morphological characters of honeybee populations from Africa.

\section{MATERIALS AND METHODS}

Data for this study consisted of 10 morphological characters measured for 18248 individual bees collected from 268 local populations in Africa (Fig. 1). Characters analysed were: length of cover hair on tergite 5 (HAIR), length of proboscis (PROB), pigmentation of tergite 2 (PIGTER2), length of sternite 3 (STERN3), width of wax plate 


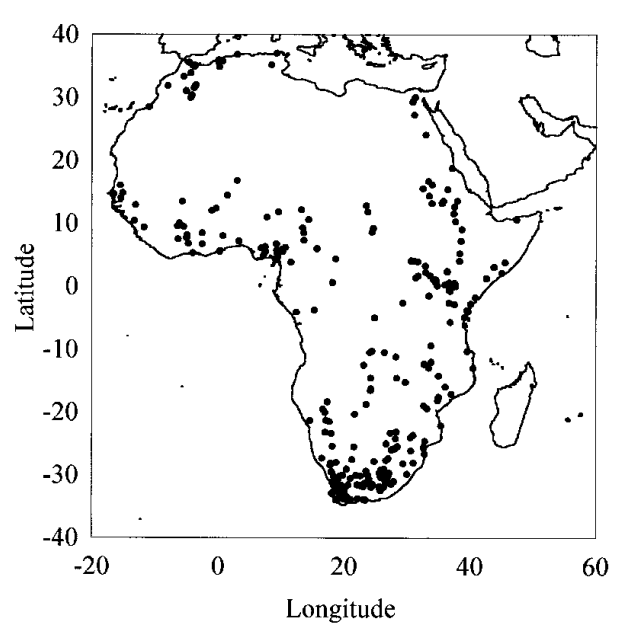

Figure 1. Localities analysed in this study for the 10 morphological variables in African honeybees.

on tergite 3 (WAXMIRR), pigmentation of scutellum (PIGSC1), pigmentation of scutellar plate (PIGSC2), wing venation angle B4 (B4), wing venation angle N23 (N23) and wing venation angle $\mathrm{O} 26$ (AO26). Detailed definitions of these characters can be found in Ruttner [20]. This large dataset was obtained by combining data obtained by one of us (R. H.) and data from the Oberursel Institute collected since the 1960s [12, 20, 21].

We analysed these data using mean vectors of local populations, without assigning a priori any local population or colony means to any subspecies. So, the main objective of the analysis was to characterise the overall spatial structure displayed by the morphological characters on a continental scale, using univariate and multivariate methods. We used several techniques of spatial analysis to achieve this purpose, and only a brief description of each method will be provided here. For further reference, readers are referred to the many recent works on spatial analyses applied to biological data [16, 23, 25, 26, 29]. Applications of these techniques to honeybee morphometrics and population biology can be found in Daly et al. [3], Diniz-Filho [4], Diniz-Filho and Bini [5], Diniz-Filho and Malaspina [6], and Diniz-Filho et al. [7].

We initially characterised the spatial patterns in the data using spatial autocorrelation analysis [23, 25, 26]. Spatial correlograms describing these patterns were constructed using Moran's I coefficients in 10 distance classes, whose upper bound limits (in $\mathrm{km}$ ) were: 638, 1 259, 1 963, 2 800, 3 419, 3 984, 4 489, 5 158, 6144 and 8 272. These limits were chosen in order to maximise the number of pairs of local populations (in this case, 3578 pairs on average) used to estimate Moran's I in each distance class [30].

Significant and positive Moran's I coefficients indicate that the populations a given distance apart were similar for the character under analysis, while significant and negative Moran's I values indicate dissimilar populations for that character at this distance. The value of each Moran's I expected under the null hypothesis of absence of spatial autocorrelation is $E(I)=-1 /(n-1)$, where $n$ is the number of local populations analysed. The statistical significance of the total number of correlograms was tested by the Bonferroni criterion, in which a correlogram is considered significant if at least one of its Moran's I is significant at $P<\alpha / k$, where $k$ is the number of distance classes and $\alpha$ is the standard type I error (5\%). We also tested the hypothesis of a monotonic or linear decrease in correlograms, indicating a clinal pattern, by computing Pearson $(r)$ or Spearman $\left(r_{\mathrm{S}}\right)$ correlations between Moran's I coefficients and the respective midpoint of the geographic distance class.

We compared the correlograms by computing Manhattan distances among them, and initially tried to explain this similarity by the correlation structure among characters. The matrix with pairwise similarity among correlograms was analysed by UPGMA (unweighted pair-group method using arithmetic averages) cluster analysis [22]. The pairwise correlations among characters were 
also analysed in a multivariate context by a factor analysis, retaining the eigenvalues larger than 1.0 and using a Varimax rotation to improve the results by achieving a simple structure $[9,14]$.

Spatial patterns were also described using a canonical trend surface analysis (CTSA) $[1,4,29]$ on the same dataset. The purpose of this multivariate technique was to find orthogonal linear combinations of characters by successively maximising their correlation with geographical space, in this case defined by the latitude and longitude (and possibly by their polynomial expansions) of local populations. Canonical coefficients of the first few linear combinations can be interpreted as factor loadings, with a spatial constraint, and mapping canonical scores permits a visual inspection of multivariate spatial patterns. Univariate trend surfaces are simply multiple regressions in which the character is the response variable and the geographical coordinates are the predictors, and so the coefficient of determination $\left(R^{2}\right)$ indicates the magnitude of spatial patterns in each character. The results from univariate trend surfaces can be directly compared with those from spatial autocorrelation analysis, although the correlation structure in data indicates that a multivariate solution using CTSA is more adequate to describe spatial patterns [1].

We also analysed the morphological variation in relation to two dummy variables expressing variation in weather and vegetation, according to the maps provided by van Chi-Bonnardel [8]. Although these dummy variables do not express in detail the environmental variation to which bee populations are subjected, they are useful as a general descriptors of the main environmental patterns at continental scale, working as surrogate variables combining many unknown but highly correlated ecological variables [17]. So, it was possible to explain variation in original characters and multivariate scores by them, using a model II analysis of variance (ANOVA)
[24]. Also, a dummy variable based on the subspecific classification presented in Hepburn and Radloff [12] was also generated, by allocating each local population to the subspecies predominant in the locality. This dummy variable is an oversimplification, since it ignores the possible continuous variation within subspecies and the hybrid zones, but it reflects the general patterns of subspecific classification and large scale population differentiation. Variance components of ANOVA were used to estimate the percentage of explanation of each effect on the morphological characters; and the residuals of the model, using subspecies groups as a classification criterion, were also submitted to autocorrelation analyses as previously discussed, to investigate within-subspecies variation.

\section{RESULTS}

Out of 100 Moran's I coefficients calculated for the dataset $(10$ characters $\times 10$ distance classes), 87 were significant at the $5 \%$ level or less. All correlograms were significant according to the Bonferroni criterion. So, strong spatial patterns are present in the data, and the shape (profiles) of correlograms (Fig. 2) can be used to establish these patterns. The average correlogram indicates that Moran's I declines with increasing geographical distance $\left(r=-0.628 ; r_{\mathrm{S}}=-0.559\right.$, both significant at the $5 \%$ level), suggesting a general clinal pattern in which close populations are similar, with a monotonic decrease in similarity with increasing geographical distances. However, there are large differences in the profiles among characters, and the size of the similarity patch (the distance at which Moran's I becomes nonsignificant) is also different among them.

The UPGMA clustering based on Manhattan distances between pairs of correlograms indicated four distinct groups of profiles: 1) HAIR + PROB (Fig. 2a): profile with a strong local autocorrelation followed by large-scale clinal variation; 2) STERN3 

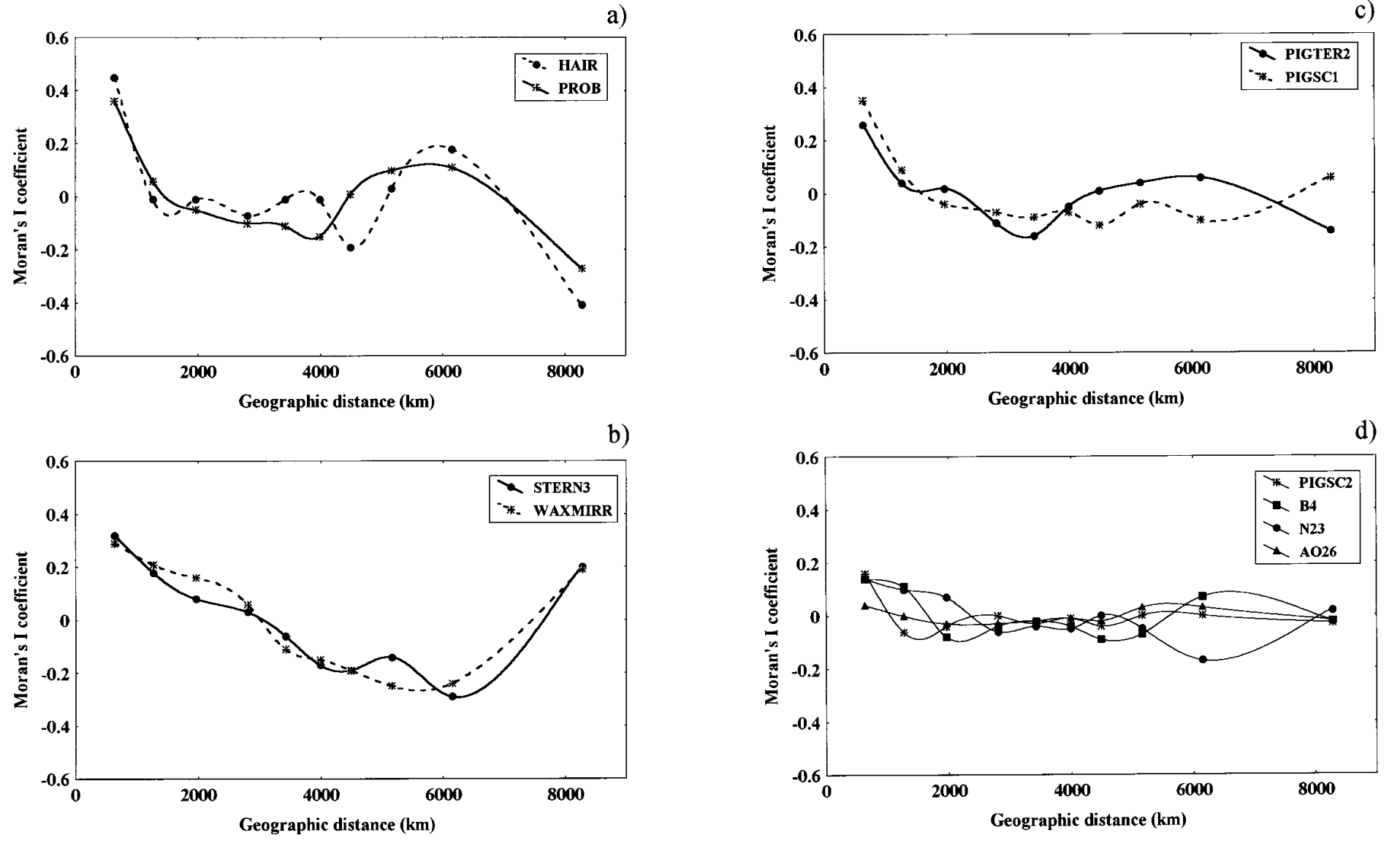

Figure 2. Spatial correlograms for the 10 morphological characters of African honeybees, grouped according to UPGMA clustering of Manhattan distances $(\mathrm{a}-\mathrm{d})$. 
+ WAXMIRR (Fig. 2b): strong local autocorrelation and clinal variation, but with a reversal in the last distance class, indicating that distant localities (in the north-south extremes of the continent) are also similar; 3) PIGSC1 + PIGTER2 (Fig. 2c): strong local autocorrelation, with distinct effects at long distances, but with low magnitude; 4) PIGSC2 + wing venation angles (Fig. 2d): weak local spatial autocorrelation.

Since correlated characters necessarily produce similar profiles in correlograms, we can explain at least a few similarities in spatial patterns by correlation among characters. This is the case for HAIR/PROB (and partially WAXMIRR), representing size characters, and for PIGTER2 and PIGSC1 for colour, and for the three wing venation angles. These patterns of correlation structure among characters in three morphological complexes are only partially observed in the loadings of Varimax rotated factors (Tab. I). The overall matrix correlation between similarity among profiles and correlation among characters, however, only tends to be slightly significant $(r=-0.135$; $P=0.143$ by the Mantel test with 1000 random permutations), indicating that at least in part uncorrelated characters can display sim- ilar profiles along the geographic space (clines or patches of similar size).

Despite the cline suggested by the average correlogram, linear or even monotonic simple trends are found for a few of the characters analysed, when the correlations between Moran's I and geographical distance class are considered. Only two characters (HAIR and N23) show linear correlations that are significant at the $10 \%$ level, and even so indicate slight trends at continental scale.

Spatial patterns in the three Varimax rotated factor scores were congruent with those in the original characters that composed them. Factor I explained around $27 \%$ of the variability in data and possessed higher loadings for PIGTER2, PIGSC1, STERN3, PIGSC2 and WAXMIRR. Its profile was similar to those in group 2 and 3 correlograms. The profile of factor II, which explained around $22 \%$ of the variability in the data and possessed higher loadings for HAIR and PROB, was similar to group 1 correlograms for original characters. Factor III, explaining $16 \%$ of the variability and composed basically of wing venation angles, showed only short distance positive autocorrelation (group 4 of correlograms).

Table I. Loadings of rotated factors and for axes derived from canonical trend surface analysis (CTSA), and fit of quadratic univariate trend surfaces $\left(R^{2}\right)$ for the 10 morphological characters of African honeybees.

\begin{tabular}{|c|c|c|c|c|c|c|c|c|}
\hline \multirow[t]{2}{*}{ Character } & \multicolumn{3}{|c|}{ Rotated factors } & \multicolumn{5}{|c|}{$C T S A$} \\
\hline & I & II & III & $R^{2}$ & I & II & III & IV \\
\hline HAIR & -0.07 & 0.71 & 0.28 & 0.33 & -0.03 & 0.84 & -0.13 & 0.02 \\
\hline PROB & -0.04 & 0.78 & 0.23 & 0.26 & 0.15 & 0.74 & 0.02 & -0.11 \\
\hline PIGTER2 & 0.82 & -0.27 & -0.07 & 0.32 & -0.56 & -0.33 & 0.59 & 0.11 \\
\hline STERN3 & -0.65 & 0.53 & -0.24 & 0.46 & 0.85 & 0.32 & -0.05 & -0.20 \\
\hline WAXMIRR & -0.54 & 0.70 & -0.18 & 0.48 & 0.78 & 0.53 & 0.26 & -0.07 \\
\hline PIGSC1 & 0.92 & -0.02 & 0.11 & 0.38 & -0.76 & 0.02 & 0.45 & -0.27 \\
\hline PIGSC2 & 0.63 & 0.09 & 0.15 & 0.10 & -0.27 & 0.05 & $0.35-$ & -0.33 \\
\hline B4 & 0.33 & 0.49 & -0.43 & 0.11 & -0.28 & 0.37 & 0.15 & -0.09 \\
\hline $\mathrm{N} 23$ & 0.26 & 0.11 & 0.75 & 0.13 & -0.33 & 0.04 & -0.19 & -0.61 \\
\hline AO26 & 0.07 & 0.15 & 0.78 & 0.01 & -0.11 & 0.05 & -0.06 & 0.03 \\
\hline
\end{tabular}


A canonical trend surface analysis (CTSA) $[4,29]$ was also applied to these data, using a quadratic expansion of the geographical coordinates on one side of the model, as suggested by the curvilinear profiles in some correlograms. According to Bartlett's sphericity test, four canonical axes are significant, i.e., express orthogonal spatial structures in data. As expected, the loadings of these four canonical axes (Tab. I) corresponded well to the groups of characters defined by factor analysis and UPGMA clustering of correlogram profiles, and maps of canonical scores permitted a better evaluation of the patterns previously described by these techniques.

The first two canonical axes possessed more clearly large-scale patterns. The first one (CTSA 1) was correlated with first rotated factor $(r=0.815 ; P<0.01)$, with positive loadings of STERN3 and WAXMIRR, and negative loadings of PIGSC 1 and PIGTER2. So, the CTSA indicated a coincidence between the main direction of morphological variation (factor I) and the spatially constrained main direction morphological variation (CTSA 1). The map of scores (Fig. 3a), interpolated using the inverse distance method algorithm, suggests that local populations at the extremes of the continent are similar for some characters (group 2 of the spatial correlograms). The loadings of geographical co-ordinates (Tab. II) on this axis indeed confirm that its more important spatial component is the latitude squared. On the other hand, the second canonical axis (CTSA 2) possesses higher loadings fOr HAIR and PROB, those characters with a linear northwestern- southeastern cline (Fig. 3b), which was supported since latitude and longitude (the linear part of the canonical model) are the geographical coordinates that are more related to this axis (Tab. II).

The third and fourth canonical axes reflect more local and regional patterns, with relatively small contributions from the geographical coordinates (Tab. II). The third one is related to group 3 correlograms (PIGTER2 and PIGSC1), while the fourth possesses a higher loading only for N23, which can be explained by the relatively weak large-scale spatial patterns in the wing venation angles. Their maps show only moderate clines, in different directions. The map of CTSA 3 (Fig. 3c) indicates a southwestnortheast cline, with similar populations in the southern and western portions of Africa. The map of CTSA 4 (Fig. 3d) seems to indicate mainly an east-west variation, differentiating A. m. scutellata and A. m. litorea from the other groups.

The determination coefficients of the quadratic univariate trend surface applied to each character (Tab. I), were congruent with expectations of their spatial patterns, as defined by the correlograms, and with the previous results of CTSA.

The results of the model II ANOVA applied to original data and factor scores, using environmental variation and subspecific classification as groups, permitted a better interpretation of these complex spatial patterns. For the environmental data (Tab. III), the characters more related to factor I, which are those with clines followed by strong or weak positive autocorrelation in the last distance class, are associated with climatic variation or vegetation, with variance components varying from 32 to $58 \%$. This can be explained by the similarity of environments in these two extremes of the continent, at least as coded for ANOVA. These results are usually similar using each dummy variable independently or combined in a two-way ANOVA (Tab. III).

On the other hand, all characters, except those in group 4 correlograms (PIGSC2 + wing venation angles), are associated with the subspecific classification, with variance components ranging from 33 to $57 \%$. The characters of wing venation and factor III are not associated with environmental patterns or with subspecific classification.

The most important aspect of the analysis of the subspecific classification using 
a)

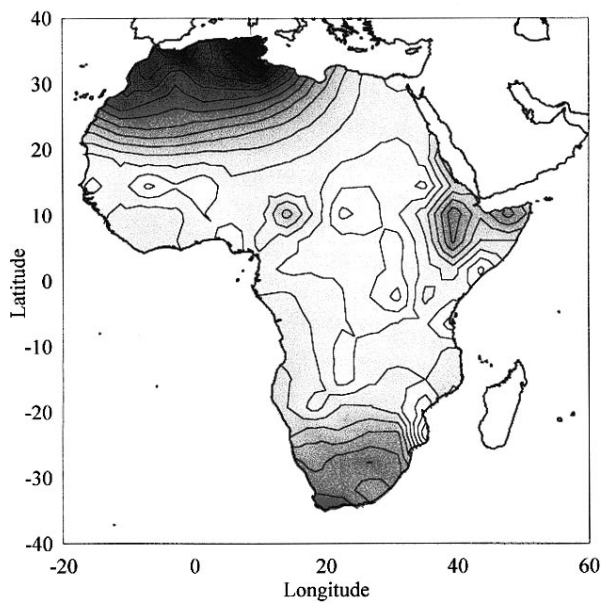

b)

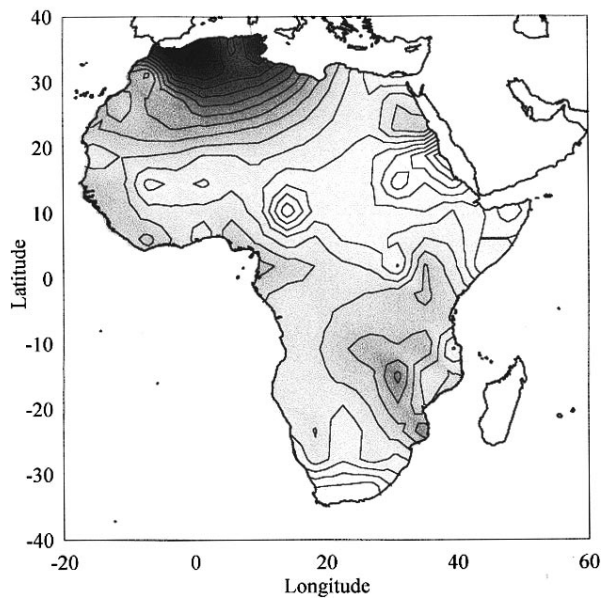

c)

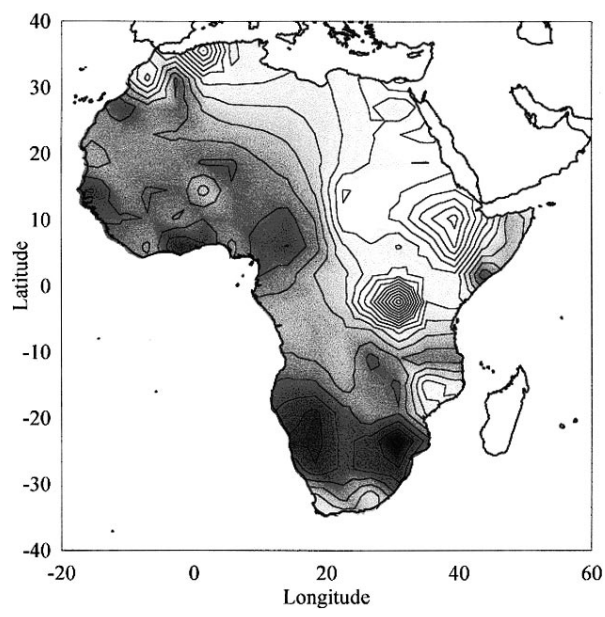

d)

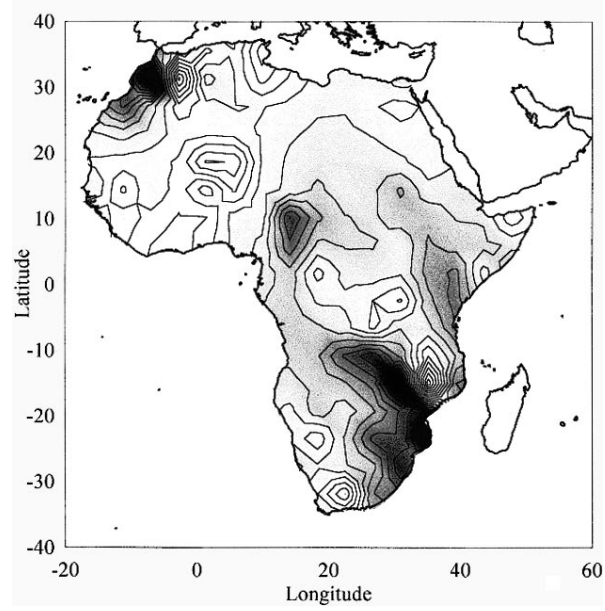

Figure 3. Interpolated surfaces using an inverse distance method algorithm for the first four canonical scores $(a-d)$.

ANOVA is that the residuals of the characters in the model are neither spatially autocorrelated nor associated with environmental variation. The variance components of environmental variation in residuals dropped in relation to those in the original data, and varied from 3 to $17 \%$ (Tab. III). The comparison of Moran's I obtained from the original data with those obtained from the residuals of the ANOVA model (Fig. 4) shows that autocorrelation decreased in such a way that most large-scale spatial structure in morphological variation can be explained by subspecific classification.

\section{DISCUSSION}

The analysis of only a few characters indicates a very rich spatial structure of 
morphological variation in African honeybees at a continental scale. Hepburn and Radloff [12] have recently pointed out that a factor analysis applied to all these samples simulaneously simply resulted in an uninterpretable blur, and so analyses had to be made on a regional scale. The richness

Table II. Correlations (in module) between CTSA scores and geographical coordinates used in the model (latitude, longitude and their quadratic expansions).

\begin{tabular}{|c|c|c|c|c|}
\hline Coordinates & CTSA 1 & CTSA 2 & CTSA 3 & CTSA 4 \\
\hline Latitude & 0.157 & 0.479 & 0.242 & 0.171 \\
\hline Longitude & 0.220 & 0.295 & 0.204 & 0.284 \\
\hline Latitude $^{2}$ & 0.731 & 0.074 & 0.029 & 0.029 \\
\hline $\begin{array}{l}\text { Latitude } \times \\
\text { Longitude }\end{array}$ & 0.354 & 0.180 & 0.332 & 0.184 \\
\hline Longitude $^{2}$ & 0.291 & 0.173 & 0.249 & 0.246 \\
\hline
\end{tabular}

detected in this study in spatial structure is exactly the reason why a traditional factor analysis did not work well with data at a continental scale, especially when trying to evaluate groups (subspecies) characterised by distinct morphological patterns in the multivariate space. However, it is important to note that mapping factor scores permits an initial investigation of the main spatial patterns in data, and they are congruent with those obtained using spatial autocorrelation analyses.

The correlation structure among characters observed in this study based on continental variation also reflects the complexity of spatial patterns, but it is interesting to note that some of these correlations, which indicate complexes of character variation (such as size, pigmentation and wing venation angles), have also been observed at smaller spatial scales $[2,13]$. These repeated

Table III. Variance components (\%) of original characters and factor and CTSA scores derived from a model II ANOVA using environmental variation (climate: CLIM and vegetation: VEG) as classification factors. Subspecific classification (SUB) was also used as classification factor, and SUB(RES) are the variance components of residuals of subspecific classification submitted to ANOVA using environmental variation as the classification factor.

\begin{tabular}{lrrrrr}
\hline Character & CLIM & VEG & CLIM + VEG & SUB & SUB(RES) \\
\hline HAIR & 5.4 & 5.6 & 9.5 & 45.6 & 6.2 \\
PROB & 11.8 & 14.8 & 21.2 & 33.3 & 17.2 \\
PIGTER2 & 44.2 & 35.1 & 46.4 & 48.2 & 14.1 \\
STERN3 & 29.2 & 33.7 & 38.5 & 49.5 & 11.8 \\
WAXMIRR & 23.0 & 28.2 & 32.3 & 57.3 & 12.1 \\
PIGSC1 & 50.5 & 48.5 & 58.9 & 51.9 & 17.7 \\
PIGSC2 & 9.5 & 12.3 & 15.9 & 12.0 & 6.3 \\
B4 & 6.3 & 8.8 & 9.8 & 13.5 & 3.1 \\
N23 & 7.7 & 12.9 & 14.3 & 9.0 & 7.2 \\
AO26 & 4.8 & 5.5 & 8.3 & 9.0 & 4.4 \\
Factor I & 47.2 & 49.2 & 56.2 & 49.7 & 15.3 \\
Factor II & 10.4 & 8.5 & 13.7 & 52.9 & 9.0 \\
Factor III & 3.3 & 9.4 & 10.3 & 8.4 & 6.4 \\
CTSA 1 & 42.9 & 53.4 & 57.6 & 53.7 & 16.0 \\
CTSA 2 & 8.9 & 6.5 & 13.8 & 54.7 & 8.7 \\
CTSA 3 & 1.4 & 1.8 & 2.4 & 17.7 & 1.4 \\
CTSA 4 & 3.2 & 4.2 & 7.3 & 7.9 & 4.9 \\
\hline
\end{tabular}




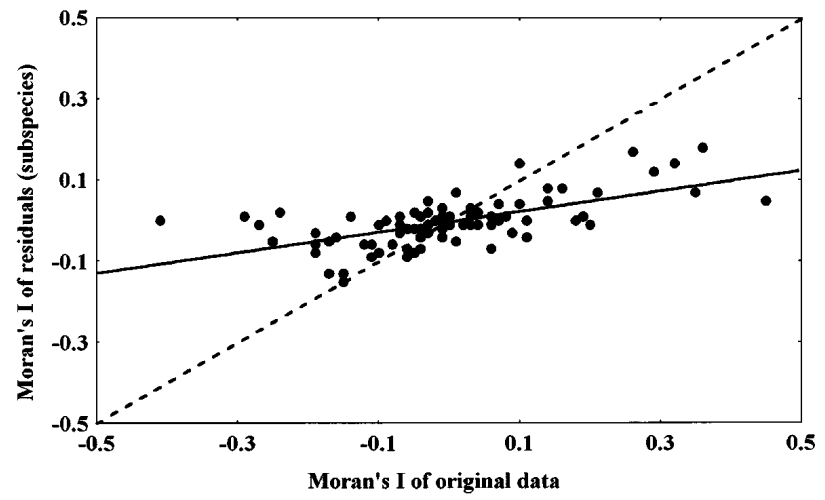

Figure 4. Relationship between Moran's I derived from original characters and from residuals of ANOVA model of subspecific classification. patterns at different spatial scales indicate an organisation pattern in terms of morphological integration that must have a common genetic basis to respond simultaneously to different microevolutionary events. However, it is important to note that this correlation structure, observed at very large spatial scales, is not that simple, as will be discussed below.

In theoretical terms, this richness in spatial structure indicates a diversity of microevolutionary processes acting in population differentiation, although it is obviously difficult to determine in detail these microevolutionary processes, based on a few characters that display complex spatial patterns. This complexity and mixture of processes is indeed expected for the natural populations of African honeybees, because of the long period of time required for natural population divergence under stochastic processes, such as local drift and isolation-by-distance, and because of the different selective agents acting through the continent, with different scales of variation in time and space. However, some initial inferences can be made by analysing spatial autocorrelation profiles and the results of ANOVA based on large-scale environmental variation.

Some characters are more associated with environmental variation, as coded by ANOVA, reflecting a long-distance morphological similarity following the relatively similar types of environment in extreme South Africa and the Mediterranean region, with step gradients in the two northsouth opposite sides of Sahara (group 2 correlograms). On the other hand, some characters possess more or less continuous north-south clines at continental scale (group 1 correlograms), a spatial pattern very common in insects and other animal groups, which has been continuously attributed to differential selective pressures related to mean temperature despite much discussion on the validity of these inferences $[10,11]$. In honeybees, these clines have been previously reported by different authors [18-20, 27]. These two large-scale patterns support adaptive divergence among phenotypes in African honeybees, tracking distinct selective agents, although gene flow among adjacent populations in secondary contacts may be also important to explain continuity in morphological variation at lower spatial scales [5]. Anyway, it is important to consider spatial autocorrelation before inferring adaptations based on a correlation between morphological and environmental covariation (see Diniz-Filho and Bini [5], and the discussion below).

On the other hand, it is interesting to note that pigmentation characters and wing venation angles do not display strong autocorrelation coefficients in the last distance 
classes of correlograms, indicating only patterns at lower (local and regional, not continental) spatial scales. This can indicate that these characters are more affected by stochastic processes at these smaller scales, although pigmentation characters, with the exception of PIGSC2, also seem to be associated with environmental variation (Tab. III).

So complexes of morphological characters usually distinguished in honeybees tend to possess different spatial patterns at large scales, reflecting the main microevolutionary processes that probably determine their variation across space. Size characters are characterised by strong long-distance spatial patterns, but with two different profiles (Figs. 2a, 2b). On the other hand, pigmentation and wing venation angles are characterised by the absence of these large-scale patterns, and the two groups of characters can be (partially) distinguished because pigmentation characters possess stronger local and regional autocorrelation (with exception of PIGSC2) (Figs. 2c, 2d).

Most characters possess relatively high variance components in the ANOVA using subspecific classification as a group, which was then structured to take into account part of the variation associated both with environmental similarity at the extremes of the continent and with the continuous northsouth cline in some characters. This association is not surprising, considering that the characters analysed here are not a random sample of honeybee phenotypic variation, and were selected by Hepburn and Radloff [12] exactly to discriminate among these subspecies. Despite this, the most important point of using this ANOVA was to investigate its residuals, which could reveal hidden structures that would partially invalidate this subspecific differentiation model. These residuals are neither spatially autocorrelated nor associated with environmental variation, indicating that the morphological variation used in the subspecific classification is well correlated with envi- ronmental variation and that, within subspecies, there are few spatial variations associated with local stochastic processes. This reinforces the general idea that these subspecies, at least as defined by these characters, are adapted to their local environmental conditions and represent integrated microevolutionary units. Thus, this procedure avoids biased adaptive interpretations generated by the presence of spatial autocorrelation.

As previously discussed, based on the correlogram profiles it is very interesting to note that variation in wing venation angles, which has usually been associated with neutral evolution $[6,28]$, is not well explained either by environmental variation or subspecific classification in Africa. However, these characters still possess local positive spatial autocorrelation (group 4 correlograms), as predicted if local stochastic variation, associated with genetic drift and shortdistance migration, is acting in population differentiation $[23,26]$. This combination of results strongly supports the neutrality of variation in these wing venation angles in African honeybees.

So the analysis of morphological data at continental scale in African honeybees suggests a rich and complex pattern of spatial variation, even considering that only variation in a few characters was investigated. This complexity of spatial patterns suggests different microevolutionary mechanisms, acting at distinct scales in time and space to generate the current morphological variation in these bees. Size characters possess different large-scale spatial patterns, while pigmentation characters and wing venation angles possess only patterns at local and regional scales. The most notable result in this sense was to show that these patterns seems to reflect a partition of phenotypic variation into adaptive and neutral components, in which some characters are associated with environmental variation and simultaneously with subspecific classification, while some are not and possess only the 
local positive spatial autocorrelation expected under stochastic microevolutionary processes associated with genetic drift and short-distance migration.

\section{ACKNOWLEDGMENT}

The work by J.A.F. Diniz-Filho was supported by a CNPq researcher fellowship.

\section{Résumé - Analyse spatiale de la varia-} tion morphologique des abeilles domestiques africaines (Apis mellifera L.) à l'échelle d'un continent. L'étude de la différentiation des populations d'abeilles domestiques africaines a été traditionnellement faite en séparant les populations en différentes sous-espèces. Suite à l'introduction des analyses multivariées dans la systématique de l'abeille domestique au cours des 30 dernières années, plusieurs typologies différentes ont été proposées. En raison de son étendue géographique considérable et de l'hétérogénéité de ses milieux, l'étude des abeilles domestiques du continent africain peut fournir des indications sur les processus microévolutifs impliqués dans la différenciation des populations lorsqu'elles sont analysées dans un contexte spatial. Les données de notre étude sont constituées par 10 caractères morphologiques mesurés sur 18248 abeilles prélevées dans 268 populations locales d'Afrique (Fig. 1). Ces caractères sont les suivants : longueur du tomentum du $5^{\mathrm{e}}$ tergite (HAIR), longueur du proboscis (PROB), pigmentation du $2^{\mathrm{e}}$ tergite (PIGTER2), longueur du $3^{\mathrm{e}}$ sternite (STERN3), largeur de la plaque cirière du $3^{\mathrm{e}}$ tergite (WAXMIRR), pigmentation du scutellum (PIGSC1) et de la plaque scutellaire (PIGSC2), angles B4, N23 et O26 de la vénation alaire (respectivement : B4, N23 et O26). Ce vaste ensemble de données a été obtenu en combinant les bases de données d'Allemagne (Oberursel) et d'Afrique du Sud (Grahamstown) [12, 20, 21]. Les corrélogrammes spatiaux ont été calculés à l'aide du coefficient d'autocorrélation I de
Moran en 10 classes de distance. Sur les 100 coefficients, 87 sont significatifs au seuil de $P<0,05$. Le corrélogramme moyen indique un cline à large échelle, dans lequel les populations locales proches sont semblables et les populations locales éloignées sont différentes. Pourtant une analyse de groupes (UPGMA : comparaison deux à deux non pondérée des moyennes arithmétiques) basée sur la distance de Manhattan entre paires de corrélogrammes a mis en évidence quatre groupes distincts de profils (Figs. 2a-2d). Les cartes générées par interpolation en minimisant les sommes des carrés pondérées par les distances pour les valeurs d'origine des caractères, les scores des facteurs et les valeurs des axes d'une analyse canonique de deuxième ordre (quadratique) confirment cette structuration (Figs. 2a-2d et Tabs. I, II). Nous avons aussi analysé les valeurs d'origine des caractères, les scores des facteurs et les axes d'une analyse canonique de deuxième ordre (CTSA) selon un modèle II d'analyses de variance (ANOVA) en utilisant la variation du milieu (climat, végétation) et la classification infraspécifique comme élements de classement (Tab. III).

L'aspect le plus important qui découle de la classification infraspécifique par ANOVA est que les résidus des variables analysées dans le modèle ne sont ni autocorrélés dans l'espace, ni associés à une variation du milieu (les composantes de la variance des résidus ont diminué et ne représentent plus que 3 à $17 \%$ ). Ceci indique que la variation morphologique utilisée dans la classification entre sous-espèces est bien corrélée avec la variation du milieu et qu'au sein d'une sous-espèce il y a peu de variations spatiales associées à des processus stochastiques locaux. Ceci renforce l'idée que ces sous-espèces, du moins telles qu'elles sont définies par les caractères en question, sont adaptées aux conditions locales et représentent des unités évolutives intégrées. Ainsi, l'analyse spatiale à l'échelle du continent africain des données morphologiques des abeilles montre une structuration riche et 
complexe, même si la variation de quelques caractères seulement a été étudiée. La complexité de la structuration spatiale suggère que différents mécanismes de microévolution ont agi à des échelles distinctes dans le temps et l'espace sur divers groupes de caractères pour générer la variation morphologique actuelle observée chez ces abeilles.

\section{Apis mellifera / biogéographie / analyse spatiale / Afrique}

Zusammenfassung - Räumlich - geographische Analyse morphologischer Variation der afrikanischen Honigbienen (Apis mellifera L.) im kontinentalen Maßstab. Untersuchungen über die Differenzierung innerhalb der afrikanischen Honigbienenpopulation beruhten traditionell auf einer Unterteilung in verschiedene Subspezies (Unterarten). Nach der Einführung multivariater Methoden in die Systematik der Honigbienen während der letzten 30 Jahre wurden mehrere unterschiedliche Typologien vorgeschlagen. Wegen der großen geographischen Ausdehnung und Unterschiedlichkeit der Umweltbedingungen über den Kontinent ist die Untersuchung der afrikanischen Honigbienen geeignet, einen Einblick in die an der Differenzierung von Populationen beteiligten mikroevolutiven Prozesse zu geben. Hierzu ist allerdings erforderlich, dass diese in einem räumlichgeographischen Kontext analysiert werden. Die in dieser Untersuchung verwendeten Daten wurden an insgesamt 18248 einzelnen Arbeiterinnen aus 268 lokalen Populationen Afrikas gemessen (Abb. 1). Die erfaßten 10 Merkmale waren: Länge des Überhaars auf dem 5. Tergit (HAIR), Rüssellänge (PROB), Pigmentierung des 2. Tergit (PIGTER2), Länge des 3. Sternit (STERN3), Breite des Wachsspiegels des 3. Sternit (WAXMIRR), Pigmentierung des Scutellum (PIGSC1) und des Scutellumschildchens (PIGSC2), Flügelwinkel B4 (B4), N23 (N23) und O26 (O26). Dieser umfangreiche Datensatz wurde durch die Zusammenlegung der Datensammlungen von Oberursel (Deutschland) und Grahamstown (South Afrika) erzeugt [12, 20, 21]. Wir berechneten räumliche Korrelogramme unter Verwendung von Moran's I Koeffizient auf Basis von 10 Abstandsklassen. Von 100 berechneten Koeffizienten waren 87 mit $P<0,05$ statistisch signifikant. Das mittlere Korrelogramm zeigte ein weiträumiges Gefälle an, bei dem benachbarte Populationen ähnlicher waren als entferntliegende. Insbesondere zeigte eine Klusteranalyse (ungewichteter paarweiser Vergleich der arithmetischen Mittel, UPGMA) auf Grundlage der Manhattan Abstände zwischen Paaren von Korrelogrammen vier deutlich unterschiedliche Profilgruppen auf (Abb. 2a-2d). Kartierungen von Originalwerten der Merkmale, von den Faktorwerten und von den Achsenwerten einer kanonischen Trendanalyse zweiter (quadratischer) Ordnung bestätigten diese Strukturierung (Abb. 2 a-2d, Tab. I, II). Wir untersuchten weiterhin die Originalwerte der Merkmale, die Faktorwerte und die Werte auf den Achsen der kanonischen Trendoberflächenanalyse (CTSA) mit einer Modell II Varianzanalyse (ANOVA) gruppiert nach Ortskategorien großräumiger Unterschiede der Vegetation, des Klimas und der Unterartklassifikation. (Tab. III). Der bedeutsamste Aspekt der Analyse der Unterartklassifikation war, dass die Residuen der Merkmale räumlich nicht autokorreliert und nicht mit den Umweltvariablen assoziiert waren (die Varianzkomponenten der Residuen verringerten sich auf Werte zwischen 3 und $17 \%$ ). Dies zeigt an, dass die der Unterartklassifikation zugrundeliegende morphometrische Variation in engem Zusammenhang mit der Variation der Umweltvariation, und dass weiterhin innerhalb der jeweiligen Unterarten nur geringe räumliche, mit lokalen stochastischen Prozessen verbundene Variation besteht. Dies unterstützt die Auffassung, dass diese Unterarten, zumindest soweit sie durch die hier verwendeten Merkmale charakterisiert werden, an die Umweltbedingungen 
adaptierte integrale evolutionäre Einheiten darstellen. Die räumlich-geographische Analyse bereits von wenigen morphometrischen Daten afrikanischer Bienen im kontinentalen Maßstab zeigt daher eine reiche und komplexe Strukturierung auf, bei der die derzeitige Variation dieser Bienen durch verschiedenartige mikroevolutive Mechanismen jeweils auf unterschiedlichen räumlichen und zeitlichen Abstandsskalen generiert wurde.

\section{Apis mellifera / Afrika / Biogeographie / räumliche Analyse}

\section{REFERENCES}

[1] Bocquet-Appel J.P., Sokal R.R., Spatial autocorrelation analysis of trend residuals in biological data, Syst. Zool. 38 (1989) 333-341.

[2] Crewe R.M., Hepburn H.R., Moritz R.F.A., Morphometric analysis of 2 Southern African races of honeybee, Apidologie 25 (1994) 61-70.

[3] Daly H.V., Hoelmer K., Gambino P., Clinal geographic variation in feral honey bees in California, USA, Apidologie 22 (1991) 591-609.

[4] Diniz-Filho J.A.F., Canonical trend surface analysis of morphometric variation in Africanized honey bees from Brazil, J. Apic. Res. 34 (1995) 65-72.

[5] Diniz-Filho J.A.F., Bini L.M., Space-free correlation between morphometric and climatic data: a multivariate analysis of Africanized honey bees (Apis mellifera L.) in Brazil, Global Ecol. Biogeogr. Lett. 4 (1994) 195-202.

[6] Diniz-Filho J.A.F., Malaspina O., Evolution and population structure of Africanized honey bees in Brazil: evidence from spatial analysis of morphometric data, Evolution 49 (1995) 1172-1179.

[7] Diniz-Filho J.A.F., Malaspina O., Pignata M.I.B., Geographic variation in Apis cerana indica F.: a spatial autocorrelation analysis of morphometric patterns, J. Apic. Res. 32 (1993) 65-72.

[8] Chi-Bonardel van R., The Atlas of Africa, Jeune Afrique, Paris, 1973, France.

[9] Harris R.J., A Primer of Multivariate Statistics, Academic Press, New York, 1975.

[10] Hawkins B.A., Latitudinal body size gradients for the bees of the eastern United States, Ecol. Entomol. 20 (1995) 195-198.

[11] Hawkins B.A., Lawton J.H., Latitudinal patterns in butterfly body sizes: is there a general pattern? Oecologia 102 (1995) 31-36.

[12] Hepburn H.R., Radloff S.E., Honeybees of Africa, Springer-Verlag, Berlin, 1998.
[13] Hepburn H.R., Radloff S.E., Morphometric and pheromonal analyses of Apis mellifera L. along a transect from the Sahara to the Pyrenees, Apidologie 27 (1996) 35-45.

[14] Johnson R.A., Wichern D.W., Applied Multivariate Statistical Analysis, Prentice-Hall, London, 1992.

[15] Kerr W.E., Portugal-Araújo V., Raças de abelhas de Africa, Garcia de Orta 6 (1958) 53-59.

[16] Legendre P., Spatial autocorrelation: trouble or new paradigma? Ecology 74 (1993) 1659-1673

[17] Pagel M.D., May R.D., Colie A.R., Ecological aspects of the geographic distribution and diversity of mammalian species, Am. Nat. 137 (1991) 791-815.

[18] Radloff S.E, Hepburn H.R., The matter of sampling distance and confidence levels in the subspecific classification of honeybees, Apis mellifera L., Apidologie 29 (1998) 491-501.

[19] Radloff S.E, Hepburn H.R, Fuchs S., Ecological and morphological differentiation of the honeybees, Apis mellifera Linnaeus (Hymenoptera: Apidae), of West Africa, Afr. Entomol. 6 (1998) 17-23.

[20] Ruttner F., Biogeography and Taxonomy of Honey Bees, Springer-Verlag, New York, 1988.

[21] Ruttner F., Tassencourt L., Louveaux J., Biometrical statistical analysis of the geographic variability of Apis mellifera L.. I. Material and methods, Apidologie 9 (1978) 363-381.

[22] Sneath P.H.A., Sokal R.R., Numerical Taxonomy, W.H. Freeman, San Francisco, CA, 1973.

[23] Sokal R.R., Jacquez G.M., Testing inferences about microevolutionary processes by means of spatial autocorrelation analysis, Evolution 45 (1991) 152-168.

[24] Sokal R.R., Rohlf F.J., Biometry, 3rd ed., W.H. Freeman, New York, 1995.

[25] Sokal R.R., Oden N.L., Spatial autocorrelation in biology. 1. Methodology, Biol. J. Linn. Soc. 10 (1978) 119-228.

[26] Sokal R.R., Oden N.L., Spatial autocorrelation in biology. 2. Some biological implications and four applications of evolutionary and ecological interest, Biol. J. Linn. Soc. 10 (1978) 229-249.

[27] Verma L.R., Mattu V.K., Daly H.V., Multivariate morphometrics of the Indian honeybee in the northwest Himalayan region, Apidologie 25 (1994) 203-223.

[28] Wagner G.P., A comparative study of morphological integration in Apis mellifera (Insecta, Hymenoptera), Z. Zool. Syst. Evol.-Forsch. 28 (1990) 48-61.

[29] Wartenberg D., Canonical trend surface analysis: a method for describing geographic patterns, Syst. Zool. 34 (1985) 259-279.

[30] Wartenberg D., SAAP: Spatial Autocorrelation Analysis Program, Exeter Publ., New York, 1989. 